\title{
El tratamiento con ácido fólico y vitamina B12 aumenta el riesgo de cáncer en pacientes con cardiopatía isquémica
}

Treatment with folic acid plus vitamin B12 increase the cancer risk in patients with ischemic heart disease

Ebbing M, et al. JAMA 2009;302(19):2119-26.

\section{Objetivo}

Evaluar la incidencia de cáncer y todas las causas de muerte luego del tratamiento con ácido fólico y vitamina $B_{12}$ en pacientes con cardiopatía isquémica.

\section{Diseño y lugar}

Combinación de 2 ensayos clínicos aleatorizados, doble ciego y controlados, realizados en Noruega (país que no cuenta con fortificación de alimentos con ácido fólico), entre 1998 y 2005. La media de seguimiento fue 39 meses y 38 meses adicionales luego del ensayo.

\section{Participantes e intervención}

Se aleatorizaron 6.837 pacientes con antecedentes de cardiopatía isquémica en 4 grupos de tratamiento oral con:

- ácido fólico: 0,8 mg/día + vitamina B12: 0,4 mg/día + vitamina B6: $40 \mathrm{mg} /$ día $(\mathrm{n}=1.708)$.

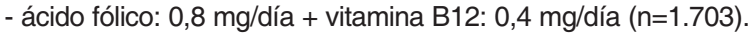

- vitamina B6: 40 mg/día ( $\mathrm{n=1.705)}$.

- placebo $(n=1.721)$.

La edad media fue de 62,3 años, el $23,5 \%$ eran mujeres, hubo menos fumadores en el grupo ácido fólico $(38 \%)$ que en el grupo no ácido fólico (41\%). Durante el seguimiento, los niveles sanguíneos de ácido fólico aumentaron entre 4 a 6 veces en relación a los basales. Se excluyeron pacientes con cáncer al momento de la aleatorización pero no aquellos con antecedentes de cáncer curado $(4,3 \%)$.

\section{Medición de resultados principales}

Datos de incidencia y mortalidad por cáncer y mortalidad global, obtenidos de registros nacionales. Se excluyó el cáncer de piel no melanoma.

\section{Resultados principales}

Tras el seguimiento extendido se observó una asociación estadísticamente significativa entre la combinación del ácido fólico + vitamina $B_{12}$ y un incremento en la incidencia de cáncer y de muerte. (Tabla 1).

Tabla 1. Incidencia y mortalidad asociadas al uso de ácido fólico y vitamina $\mathrm{B}_{12}$

\begin{tabular}{c|c|c|c|c} 
Resultados & $\begin{array}{c}\text { Fólico+ } \\
\mathbf{n = 3 . 4 1 1}\end{array}$ & $\begin{array}{c}\text { Control } \\
\mathbf{n = 3 . 4 2 6}\end{array}$ & HR $^{*}$ & NNT $^{*}$ \\
\hline Incidencia de cáncer & $341(10 \%)$ & $288(8,4 \%)$ & $1,21(1,03-1,41)$ & $63(33-500)$ \\
\hline Mortalidad por cáncer & $136(4 \%)$ & $100(2,9 \%)$ & $1,38(1,07-1,79)$ & $94(53-500)$ \\
\hline Mortalidad global & $548(16,1 \%)$ & $473(13,8 \%)$ & $1,18(1,04-1,33)$ & $44(26-167)$ \\
\hline
\end{tabular}

HR: Hazard ratio; NNT: Número Necesario para Tratar.

\section{Conclusiones}

El tratamiento con ácido fólico más vitamina $B_{12}$ se asoció a un incremento de la mortalidad global y por cáncer en pacientes con cardiopatía isquémica, residentes en un país sin fortificación de alimentos.

Palabras claves: Ácido fólico, vitamina B, cáncer, mortalidad.

Key words: folic acid, vitamin B(12), cancer, mortality.

Fuente de financiamiento: diversas instituciones gubernamentales y universitarias noruegas.

\section{Comentario}

Desde 1998, muchos países han implementado la fortificación de harinas y cereales con ácido fólico para reducir el riesgo de defectos congénitos del tubo neural. ${ }^{1}$ Desde entonces ha surgido preocupación en relación a la seguridad del ácido fólico y su potencial favorecedor de la carcinogénesis.

Este primer seguimiento a largo plazo luego de la suplementación, con una pérdida mínima de participantes, se encontró que más pacientes suplementados murieron o contrajeron algún tipo de cáncer, principalmente de pulmón, que los que no lo recibieron.

Sin embargo, una de las limitaciones de este estudio consiste en no haber investigado los antecedentes familiares de cáncer u otros factores de riesgo que promuevan la carcinogénesis, aunque el gran tamaño de la muestra y el balance de múltiples características alcanzado por la aleatorización sugieren una distribución similar en ambos grupos. Por otra parte, en el período de seguimiento posterior no se comprobó una alta adherencia, por lo que se desconoce el tiempo real de exposición a las vitaminas.

\section{Conclusiones de la comentadora}

$\mathrm{Si}$ bien estos resultados necesitan ser confirmados en otras poblaciones, teniendo en cuenta que las dosis usadas en este trabajo duplicaron las recomendadas para fortificar alimentos, esta información sugiere la necesidad de implementar estrategias de monitoreo poblacional de seguridad del ácido fólico sobre todo en lugares donde la fortificación de alimentos es obligatoria..$^{3-4}$

Mariana Di Rosso [ Servicio de Medicina Familiar y Comunitaria. Hospital Italiano de Buenos Aires ]

Di Rosso M. El tratamiento con ácido fólico y vitamina B12 aumenta el riesgo de cáncer en pacientes con cardiopatía isquémica. Evid. actual. práct. ambul; 13(2): 58, Abril-Jun 2010. Ebbing M, et al. Cancer incidence and mortality after treatment with folic acid and vitamin B12. JAMA 2009;302(19):2119-26. PMID: 19920236

\section{Referencias}

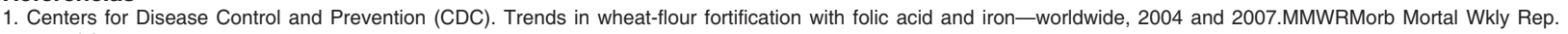
2008;57(1):8-10.

2. Smith AD, Kim YI, Refsum H. Is folic acid good for everyone? Am J Clin Nutr. 2008;87(3):517-533.

3. Kalmbach RD, Choumenkovitch SF, Troen AM, D'Agostino R, Jacques PF, Selhub J. Circulating folic

acid in plasma: relation to folic acid fortification. Am J Clin Nutr. 2008;88(3):763-768.

4. Rosenberg IH. Science-based micronutrient fortification: which nutrients, how much, and how to know? Am J Clin Nutr. 2005;82(2):279-280. 